\title{
"Por que aprender isso, professora?" Sentido pessoal e atividade de estudo na Psicologia Histórico-Cultural
}

\author{
Flávia da Silva Ferreira Asbahr \\ Universidade Estadual Júlio de Mesquita Filho \\ Marilene Proença Rebello de Souza \\ Universidade de São Paulo
}

\begin{abstract}
Resumo
Esta pesquisa investigou o processo de atribuição de sentido pessoal à atividade de estudo de estudantes do Ensino Fundamental. A referência teórica é a Psicologia Histórico-Cultural. Foi realizada com estudantes de 4⿳a série de uma escola pública. Os procedimentos metodológicos foram: observação do cotidiano de uma turma; situações orientadas de aprendizagem; grupos focais; entrevistas. Como resultado, buscou-se delimitar a unidade de análise: a relação entre os motivos da atividade de estudo e os fins das ações de estudo. Defende-se a tese de que, para que a aprendizagem escolar ocorra, as ações de estudo dos estudantes devem ter um sentido pessoal correspondente aos motivos e aos significados sociais da atividade de estudo, no sentido da promoção do desenvolvimento humano.
\end{abstract}

Palavras-chaves: atividade escolar; psicologia histórico-cultural; ensino fundamental.

\begin{abstract}
"Why do I need lo learn this, teacher?" Personal sense and study activity in Historic-Cultural Psychology. This research investigated the process of personal sense attribution to the study activity of students in Elementary School. The theoretical reference is the Historical-Cultural Psychology. It was conducted with students from 4th grade in a public school. The methodological procedures were: observation the daily life of a classroom; learning oriented situations; focus groups; interviews. As a result, we sought to define the analysis unit: the relation between the study activity motives and the objectives of study actions. It is defended the thesis that for the scholar learning to happen, the study actions of the students must have a personal sense correspondent to the motives and to the social meanings of the study activity, towards the human development promotion.
\end{abstract}

Keywords: school activity; historic-cultural psychology; fundamental education.

\section{Resumen}

“Por qué aprender esto, maestra? "El sentido personal y la actividad de estudio en la Psicología Histórico-Cultural. Se investigó el proceso de asignar un sentido personal a la actividad de estudio de estudiantes de primaria. La referencia teórica es la Psicología Histórico-Cultural. La investigación se desarrollo con estudiantes de cuarto grado en una escuela pública. Los procedimientos metodológicos fueron: observación de la vida cotidiana de una clase; situaciones orientadas de aprendizaje; grupos de discusión; entrevistas. Como resultado, hemos tratado de definir la unidad de análisis: la relación entre los motivos de la actividad de estudio y los fines de las acciones. Para producir el aprendizaje escolar, se defiende la tesis de que las acciones de estudio de los estudiantes deben tener un sentido personal correspondiente a los motivos y los significados sociales de la actividad de estudio, en la dirección de la promoción del desarrollo humano.

Palabras claves: actividad escolar; psicología histórico-cultural; enseñanza fundamental.

C6 Professor, por que eu tenho que aprender isso?"; "Para que vou usar isso que estou aprendendo na minha vida?". Frases como essas, ditas por estudantes de escolas em que trabalhamos e por nós mesmos durante a vida escolar produzem angústias e inquietações, pontos de partida desta investigação e de suas questões de pesquisa:
Qual é o sentido pessoal que os estudantes atribuem a sua vida escolar? Mais especificamente, qual é o sentido pessoal atribuído a sua atividade de estudo?

Como sabemos, a escola pública brasileira sofre graves problemas no que diz respeito aos processos de escolarização, ensino e aprendizagem. Pesquisas indicam que, a partir Acervo disponivel em: www.scielo.br/epsic 
da década de 1990, o acesso à escola foi, em grande medida, universalizado (Lima, 2011) e podemos dizer que as crianças em idade escolar estão, em sua maioria, matriculadas na escola. Mas, por outro, as condições de permanência e aprendizagem não estão consolidadas. Ainda nos deparamos com o grave problema da reprovação em muitos Estados e municípios brasileiros, já fortemente denunciado por Patto (1999), Paro (2001) e outros autores. Também nos deparamos com as consequências desastrosas de políticas que visam eliminar a reprovação sem eliminar suas causas, produzindo alunos semialfabetizados em todos os níveis do Ensino Básico (Bertagna, 2010; Viégas, 2007).

Diante desse cenário, pesquisadores brasileiros têm investigado as políticas públicas em educação, a formação de professores, a produção do fracasso escolar, a gestão escolar, entre outras temáticas, buscando compreender as repercussões desses elementos no cotidiano da escola e na aprendizagem discente. Mas há outros temas ainda a serem abordados, como, por exemplo, compreender como os estudantes avaliam seu próprio processo de escolarização, ou seja, entender a escola a partir da análise dos estudantes.

Nessa perspectiva, a Psicologia Escolar e Educacional pode fornecer importantes contribuições na medida em que tem se dedicado a investigar como os próprios sujeitos que estudam e trabalham nas escolas explicam o processo de escolarização e, especialmente, como as crianças entendem e vivenciam sua história escolar, como vemos em Souza (2010).

Dentre as várias abordagens teóricas da Psicologia que buscam compreender os fenômenos escolares de forma crítica, a referência teórica adotada é a Psicologia Histórico-Cultural, cujos principais representantes são Vigotski, Leontiev, Luria, entre outros. Tal concepção tem o método materialista histórico dialético de Marx como origem filosófica e epistemológica e como projeto a elaboração de uma psicologia concreta do homem (Vigotski, 1929/2000a).

Um dos conceitos fundamentais desta abordagem é o de sentido pessoal (Leontiev, 1974/1983), compreendido a partir da unidade dialética entre a atividade humana e a consciência. O sentido pessoal expressa a relação subjetiva que o sujeito estabelece com os significados sociais e com as atividades humanas. É o conceito-chave do presente trabalho, pois permite compreender como é a relação que as crianças estabelecem com o estudo, entendendo a escola a partir da análise dos estudantes.

Tanto na literatura pedagógica como na psicológica, assistimos a um aumento de produções e pesquisas tendo como referência o conceito de sentido pessoal. Surgem, nesta perspectiva, artigos que fazem uma revisão teórica acerca dos conceitos de sentido pessoal, significado social e sua relação com demais conceitos da psicologia histórico-cultural, mas que não trazem dados de pesquisa sobre o tema (Aguiar \& Davis, 2011; Asbahr, 2011; Barros, Paula, Pascual, Colaço, \& Ximenes, 2010; Rey, 2009, entre outros).

No caso desta pesquisa, o ponto de partida é a compreensão de que o sentido pessoal é produzido na relação com a atividade humana e, portanto, para que os sentidos pessoais possam ser analisados torna-se essencial compreendê-los a partir da estrutura da atividade humana (Leontiev, 1974/1983; Martins \& Eidt, 2010). Assim, nosso objetivo é investigar o processo de atribuição de sentido pessoal à atividade de estudo de estudantes do Ensino Fundamental.

\section{Método}

Os participantes da pesquisa foram estudantes de $4^{a}$ série do Ensino Fundamental de uma escola pública na cidade de São Paulo. Tal série foi escolhida porque os estudantes estão no final do primeiro ciclo de escolarização, o que possibilita uma análise mais ampla dessa fase do ensino. A $4^{a}$ série onde foi desenvolvida a pesquisa era composta por 23 alunos, sendo 16 meninos e sete meninas, com idade média de dez anos. A turma foi acompanhada durante um ano letivo, tendo como foco a dinâmica da classe, a organização das atividades pedagógicas, a relação professor-aluno, a relação entre os alunos e as formas singulares com as quais os estudantes lidam com sua própria atividade de estudo.

O trabalho de campo constituiu-se em permanência prolongada e convivência intensa (Rockwell, 2009) com os estudantes e profissionais da escola por meio do acompanhamento e observação do cotidiano escolar, principalmente da sala de aula, o que foi essencial para a compreensão de como se estrutura a atividade de estudo.

Concomitante à observação do cotidiano escolar, como decorrência das proposições vigotskianas acerca do método genético-causal, foram criadas situações de ajuda aos estudantes participantes da pesquisa durante a realização das tarefas pedagógicas realizadas em sala de aula, de modo que pudéssemos acompanhar e compreender seu processo de desenvolvimento e aprendizagem. Denominamos essa estratégia de situação orientada de aprendizagem.

Outra estratégia metodológica foi a realização de grupos focais (Gatti, 2005) com as crianças, com o objetivo de ampliar a compreensão do processo de atribuição de sentido pessoal não apenas como um fenômeno individual, mas de constituição coletiva. Participaram desta etapa 18 crianças. Dessa forma, a turma foi dividida em dois grupos de nove crianças e cada grupo participou de três encontros. Nos grupos, discutiu-se os seguintes temas: escola e processo de escolarização; processo de aprendizagem e conteúdos escolares; relações humanas na escola.

Também entrevistamos oito crianças e a professora da turma, com a finalidade de aprofundar os temas discutidos nos grupos focais e explorar questões particulares de cada estudante. A entrevista foi organizada a partir de três grandes temas: a vida, a escola e o futuro. A entrevista com a professora da classe teve como objetivo compreender a relação entre a atividade pedagógica e a atividade de estudo.

Em síntese, em termos de procedimentos metodológicos para a apreensão dos dados, a pesquisa de campo dividiu-se em quatro momentos: acompanhamento e observação do cotidiano de uma turma de $4^{\text {a }}$ série; situações orientadas de aprendizagem; grupos focais com os estudantes; entrevistas individuais com algumas crianças e com a professora. 
Com uma grande quantidade de dados em mãos, surgem algumas indagações: como organizá-los? Como analisá-los? Como utilizá-los para explicar o processo de atribuição de sentido pessoal?

O primeiro momento de análise ocorreu ainda durante a pesquisa de campo, em que procuramos dar sentido ao emaranhado caótico de dados. A primeira organização dos dados, caracterizada como uma descrição empírica foi produzida a partir da leitura exaustiva dos registros de pesquisa e pautouse no levantamento das temáticas mais frequentes que apareciam no cotidiano da turma.

Depois, buscou-se superar a descrição empírica e construir categorias analíticas que superassem o concreto caótico. Assim, elaboramos três eixos de análise que pudessem apreender o movimento da atividade de estudo e o sentido a ela atribuído: a) contexto da atividade de estudo; b) desenvolvimento da atividade de estudo; c) resultados da atividade de estudo. Esses eixos correspondem ao movimento de constituição da atividade de estudo e ao processo de atribuição de sentido pessoal relacionado.

Ainda que tal organização, em eixos de análise, permitisse uma maior compreensão do movimento de atribuição de sentido pessoal à atividade em foco, ainda permanecia em um nível descritivo. Faltava a esse movimento a delimitação do que é essencial ao processo de atribuição de sentido pessoal à atividade de estudo, ou seja, o estabelecimento da unidade de análise do objeto investigado.

Desse momento, surgiram outras questões: qual é a unidade de análise que permite explicar o processo de atribuição de sentido pessoal? Quais são as abstrações necessárias para que se ascenda do concreto caótico para o concreto pensado, no caso da pesquisa em foco?

Essas questões direcionam-nos para o terceiro movimento de análise que é a reconstrução do concreto mediado pelas abstrações, como aponta Marx (1857/1989), ou unidade de análise, nas palavras de Vigotski (1934/2000). Entendemos que não é possível desmembrar a relação entre o motivo da atividade de estudo e a ação de estudo na análise do processo de atribuição de sentido pessoal. Segundo Leontiev (1974/1983), o sentido é criado na relação entre o motivo da atividade e aquilo para o qual a ação do sujeito está orientada como resultado possível, ou seja, seu fim. Na ação consciente, estão integrados a gênese da atividade (motivo) e o objeto da ação (fim da ação).

Assim, se quisermos analisar a atribuição de sentido pessoal a qualquer atividade, é necessário encontrar os motivos dessa atividade e quais são as ações que correspondem a esta atividade. Observa-se que essa unidade de análise relaciona-se diretamente com a estrutura da atividade e da consciência, integrando-as. É possível, então, reconstruir a realidade no pensamento e explicá-la, mas agora num outro nível de concretude, o concreto pensado, síntese de múltiplas determinações. Neste sentido, na apresentação dos resultados, toma-se a unidade de análise, a relação entre o motivo da atividade de estudo e a ação de estudo, como referência para a apresentação dos dados. Assim, os dados não são apresentados como mera descrição dos fenômenos observados na escola, mas sim foram reconstruídos tendo os conceitos de motivo e ação como abstrações auxiliares ao movimento de ascensão do abstrato ao concreto.

\section{Resultados e discussão}

Tendo como referência princípios metodológicos da Psicologia Histórico-Cultural, advindos do método materialista histórico dialético, que orientaram esta pesquisa, neste item optamos por apresentar conjuntamente os resultados e discussões. Tal escolha é coerente aos princípios teórico-metodológicos adotados, especialmente às proposições de Marx (1857/1983) sobre o método em sua dupla determinação, investigação e exposição. O método dialético de Marx distingue, sem separar, esses dois momentos, presumindo que o objeto só pode ser exposto depois de ser investigado e analisado em suas determinações essenciais.

O momento de exposição dos dados de pesquisa pressupõe uma exposição crítica do objeto que possa expressar sua lógica interna, seu movimento de constituição como objeto. A exposição é, portanto, uma reprodução ideal do movimento efetivo do real (Marx, 1857/1983). Nesse sentido, ao apresentar os resultados tomamos como referência a unidade de análise do objeto desta investigação, a relação entre o motivo da atividade de estudo e a ação de estudo. Para reconstruir, reproduzir nosso objeto, buscamos identificar, nos dados de pesquisa, os elementos que compõem a atividade de estudo, ou seja, os motivos dessa atividade, as ações de estudo desenvolvidas e seus fins.

Comecemos pelos motivos. Ao analisar os dados, os categorizamos em motivos expressos pelas crianças e motivos vividos. Os primeiros correspondem àqueles motivos falados pelas crianças nas entrevistas ou nos grupos focais, e que, em sua maioria, estão atrelados aos significados sociais da atividade de estudo. Os segundos referem-se aos motivos vividos pelas crianças e produzidos a partir das ações desenvolvidas na própria atividade escolar, sejam de estudo ou não. Relacionam-se especialmente com a dimensão afetiva da atividade. É possível, inclusive, nomear os primeiros como motivos estímulos e os segundos como motivos geradores de sentido (Leontiev, 1944/1988). Entendemos, também, que os primeiros podem transformar-se nos segundos e vice-versa, o que nos permite vislumbrar transformações no conteúdo da atividade.

Durante a pesquisa de campo, perguntamos aos estudantes por que vinham à escola e qual era a importância da escola e do estudo em suas vidas. Os motivos expressos por praticamente todas as crianças referem-se à preparação para o mercado de trabalho e a seu futuro quando adultas. Nati, uma das alunas cujo nome é fictício, explica a finalidade da escola:

Nati: Vai servir quando eu vou ser adulta, num emprego.

Pesquisador: Mas vai servir como assim, o que você pensa?

Nati: Tem conta, tipo assim, se eu for trabalhar num caixa, eu vou saber contar dinheiro e pra outras coisas (Entrevista com Nati). 
Mesmo quando mencionam a aprendizagem e o estudo, esses dois elementos relacionam-se com a possibilidade de ingresso no mercado de trabalho no futuro. Ou, ainda, os alunos expressam uma visão utilitária do conhecimento. Paro (1999), em suas pesquisas, também observa o quanto a função da escola está relacionada com a obtenção de um trabalho no futuro, especialmente para a classe trabalhadora. O autor questiona se o preparo para o trabalho deve mesmo ser a função da escola. Postula, a partir de uma concepção marxista, que o trabalho é a mediação que o homem necessita para se constituir historicamente. Porém, no modo de produção capitalista, o trabalho, que adquire amplamente a forma de emprego, é fonte de aniquilamento do ser humano como sujeito. Nesse sentido, Paro remete-nos ao conceito de alienação e analisa que preparar para o trabalho, em nossa sociedade, significa preparar para o mercado de trabalho, para a exploração e a alienação. A escola deixa, assim, de contribuir para a formação de um homem humanizado e livre.

No caso desta pesquisa, quando se analisa a relação desse motivo, preparar para o trabalho e as ações realizadas, vemos um forte hiato, uma ruptura, pois as ações não correspondem a esse motivo, nem ao menos no nível analisado por Paro, ou seja, os motivos "preparar para o trabalho" não correspondem às ações realizadas. E, mais importante, esses motivos são externos à atividade da criança, não ocupam um lugar estrutural em sua atividade, seja porque o ingresso no mercado de trabalho ainda está distante de suas vidas, seja porque os conhecimentos escolares pouco se relacionam com a atuação profissional. Esses motivos cumprem, assim, a função de motivos apenas compreensíveis e contribuem para o esvaziamento do processo de atribuição de sentido pessoal à atividade de estudo.

Nas entrevistas e encontros em grupos com as crianças, outro motivo declarado da atividade de estudo refere-se às questões disciplinares: estuda-se para evitar a reprovação, para evitar broncas da professora ou para evitar castigos, como ficar sem ir à quadra ou à aula de Educação Física.

Mas será que as ações realizadas frente a esses motivos correspondem a ações de estudo e produzem aprendizagem? As observações em sala de aula indicam que não. Ao contrário, mostram-nos que são ações cujos fins visam muito mais evitar situações negativas vivenciadas na escola (broncas, castigos, reprovação) do que de fato aprender.

Uma das perguntas realizadas nas conversas com as crianças referiu-se à obrigatoriedade de vir à escola. Poucas crianças responderam que não viriam mais se a escola deixasse de ser obrigatória, a maioria disse que continuaria vindo porque a escola é um lugar onde podem encontrar os amigos e se divertir. Quando perguntamos sobre como seria uma escola ideal, também aparece a ideia da escola ligada à diversão, à possibilidade de encontrar os amigos.

Aqui encontramos um motivo importante, não apenas declarado pelas crianças, mas principalmente vivido. É um motivo afetivo relacionado à presença do outro, e que, embora não se relacione diretamente à atividade de estudo, deve ser considerado na organização da atividade pedagógica. Na análise desse motivo, há duas questões teóricas de suma importância: o papel do outro no desenvolvimento humano (Vigotski, 1931/1995) e a comunicação íntima pessoal como possível atividade principal dos estudantes em foco (Elkonin, 1987).

Sobre o papel do outro no desenvolvimento humano, o motivo "encontrar os amigos" ou "se divertir" não guarda relação direta com a atividade de estudo, ao contrário, a qualidade da relação entre as crianças pouco contribuía para o aprendizado escolar. Os próprios estudantes avaliam que os colegas mais atrapalham do que ajudam quando o assunto são as tarefas de estudo. Mas, dependendo de como a atividade pedagógica é organizada, esse motivo pode ser transformado em motivo de estudo. Ressalta-se aqui o papel do professor na organização de atividades pedagógicas a partir da compreensão do caráter coletivo da aprendizagem humana.

No que diz respeito à comunicação íntima pessoal, atividade principal na adolescência, entendemos que a relação com os amigos e companheiros de classe tem lugar central na formação da personalidade e, nessa perspectiva, faz todo sentido que tal relação seja um motivo importante da atividade desenvolvida na escola.

Analisando esses motivos afetivos, avalia-se que não condizem imediatamente com as ações de estudo, mas podem ser motivos realmente eficazes se forem considerados como pontos de partida e trabalhados como mediações para tal atividade. Nesse sentido, valoriza-se o papel do professor na coordenação do grupo de estudantes e na transformação desses motivos afetivos em motivos cognitivos, conforme analisado em Asbahr (2011), Leontiev (1974/1983) e Rey (2009).

A relação com a professora também aparece como um dos motivos da atividade de estudo e os alunos da classe investigada avaliam que a professora da turma, Solange, conseguiu ensiná-los e foi uma boa professora. A professora aparece como um dos elementos mais importantes na relação das crianças com o conhecimento:

A pesquisadora pergunta do que eles mais gostam da classe. Diego responde: professora, a professora, a professora. Júlio: a professora. Milla: a professora e o silêncio. Mara: eu gosto da professora e das minhas amigas. Nati diz: das minhas amigas, primeiramente, da professora e de vocês (Excerto de registro de grupo focal).

A relação com a professora e com os colegas é, assim, importante motivo vivido pelas crianças e ressalta o papel dos afetos na produção da aprendizagem escolar. A grande questão é: como transformar esse motivo em motivo eficaz para a atividade de estudo? A resposta está no resultado das ações das crianças.

Algumas crianças nos mostraram a produção de novos motivos a partir do resultado de suas ações. Ou seja, iniciam as ações de estudo tendo como referência motivos afetivos (por exemplo, satisfazer a professora), mas, no decorrer da realização das ações, o próprio processo de realização e os resultados obtidos geravam motivos hierarquicamente superiores no que diz respeito à atividade de estudo. O motivo passa a ser aprender. Leontiev (1944/1988) explica essas transformações 
de motivo e conclui que a arte da educação é justamente a transformação dos motivos apenas compreensíveis em motivos eficazes:

[...] É uma questão de o resultado da ação ser mais significativo, em certas condições, que o motivo que realmente a induziu. A criança começa fazendo conscienciosamente suas lições da casa porque ela quer sair rapidamente e brincar. No fim, isto leva a muito mais; não apenas obterá a oportunidade de brincar, mas também a de obter uma boa nota. Ocorre uma nova objetivação de suas necessidades, o que significa que elas são compreendidas em um nível mais alto (p. 70-71).

Ainda sobre os motivos, havia crianças que estabeleciam uma relação muito interessante com o conhecimento e seu motivo da atividade de estudo era realmente aprender. Crianças curiosas, com sede de conhecimento, cheias de perguntas sobre o mundo à sua volta. Infelizmente, essas necessidades de conhecer nem sempre encontravam os objetos do conhecimento na escola e, portanto, não se tornavam motivos para a atividade de estudo. Ou seja, eram estudantes que queriam aprender e queriam aprender coisas que se relacionavam com os conteúdos escolares, mas não necessariamente a forma como estes eram transmitidos satisfaziam suas necessidades. Fernando é um exemplo emblemático, uma criança cheia de curiosidades sobre temas científicos, especialmente sobre os animais, mas muito distraída nas tarefas escolares:

Fernando senta ao meu lado e novamente quer conversar sobre os bichos. Ele me pergunta sobre os peixes, quer saber como é a reprodução dos peixes-betas, pois são peixes de briga: Como é que vai colocar dois betas no mesmo aquário? Será que eles não vão brigar? Eu digo que tem a época certa e ele quer saber qual (Excerto de registro de campo).

Mas, em poucos momentos das aulas observadas, as curiosidades e questões de Fernando foram consideradas ou se tornaram matéria-prima de discussão. Pelo contrário, ele era considerado "diferente" pelo restante da turma e desatento pela professora. Sua enorme necessidade de aprender não se tornava motivo da atividade de estudo.

Além da investigação dos motivos da atividade de estudo, fundamental à compreensão do processo de atribuição de sentido pessoal, igualmente central é a investigação das ações de estudo de nossas crianças.

As ações de estudo foram classificadas em ações de conformação e ações de transformação. As primeiras referem-se às ações que reproduzem e mantêm a ordem vigente e poucas transformações produzem em termos de aprendizagem para as crianças. Nelas, evidencia-se a ruptura entre os motivos da atividade de estudo e a finalidade das ações. As segundas indicam possibilidades de transformação no que diz respeito à aprendizagem dos estudantes. Mesmo que de maneira incipiente, são ações que podem produzir capacidades e habilidades que contribuem com o processo de humanização.

Comecemos pelas ações de conformação. Um dos primeirøs fatos que chamava a atenção ao chegar nesta $4^{a}$ série era a grande quantidade de tarefas de cópias a que os estudantes eram submetidos: cópia da lousa, do livro didático, de folhinhas mimeografadas etc.
Nas entrevistas e grupos com as crianças, perguntamos o que achavam das tarefas de cópia e as respostas não foram unânimes. Havia crianças que vinham mostrar, com orgulho, o caderno cheio de páginas preenchidas, mas havia também aqueles que se recusavam a copiar. De qualquer maneira, as tarefas de cópia eram, de forma geral, feitas sem nenhuma atenção das crianças: enquanto copiavam, conversavam e brincavam com os colegas.

Ao entrevistar a professora, questionamos a finalidade das cópias. Solange apresentou várias justificativas e finalidades para essa tarefa:

Solange disse que utiliza tal estratégia porque, enquanto a turma está copiando um texto, ela pode atender individualmente os alunos. Outra razão é que a cópia é uma tarefa que os alunos podem realizar sozinhos, mesmo quando apresentam dificuldades de aprendizagem. (...) Enquanto eles copiam, ela pode atender individualmente cada aluno, pode olhar os cadernos, corrigir as lições de casa, tirar dúvidas, tomar leitura. (...) Outra razão é que o estudante sente-se estimulado ao ver seu caderno cheio, sente que produziu. A cópia ajuda também no desenvolvimento da coordenação motora e, com o tempo, o aluno fica mais hábil e ágil para escrever. Ela também acha que a cópia ajuda no desenvolvimento da leitura, pois, para copiar, o aluno precisa, de uma forma ou de outra, ler (Entrevista com a professora).

Mesmo com tantas justificativas pedagógicas, nem sempre a tarefa de cópia alcançava seus objetivos. Para muitas crianças, a cópia era operação automatizada, sem resultados em termos de aprendizagem. Dessa forma, são ações que poucas mudanças produzem nas crianças no que diz respeito à transfor-

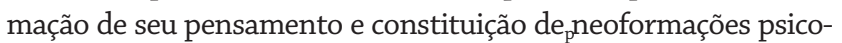
lógicas. São ações esvaziadas de sentido, como menciona Leontiev (1974/1983).

Um desdobramento dessas ações esvaziadas de sentido eram as ações de recusa. Em diversos momentos, presenciamos os estudantes recusando-se firmemente a fazer as tarefas propostas. Algumas recusas eram sutis, de forma simulada, ou seja, as crianças "fingiam" que faziam uma lição, mas se dedicavam a outras coisas, a conversar com os amigos, a escutar música com fones de ouvido, a escrever bilhetes, cartas ou, no caso das meninas, diários. Ou, ainda, esperavam o tempo passar conversando com os colegas. Essas ações também tinham a forma de desatenção em relação ao que a professora explicava ou em relação à tarefa proposta. Em outros casos, as recusas eram agressivas, na forma de provocação ou enfrentamento à professora.

Sobre as ações de transformação, referimo-nos às ações que produziam mudanças nas crianças, no sentido da constituição da atividade de estudo.

Logo em nossas primeiras observações em sala de aula, chamou-nos a atenção a vontade de aprender dessas crianças. Presenciamos diversos episódios em que as crianças realizavam ações de aprendizagem, mas não necessariamente em relação aos conteúdos escolares. Ou, ainda, era o conteúdo escolar o objeto de suas ações de aprendizagem, mas não da forma como estava sendo trabalhado pela professora. Segue um exemplo de uma aula sobre o aparelho excretor, na qual professora faz uma pequena introdução sobre o tema, escreve um 
texto na lousa a ser copiado, entrega folhinhas mimeografadas com o desenho dos órgãos e mostra um modelo anatômico do corpo humano, apontando os órgãos responsáveis pela excreção. Os estudantes copiavam o texto da lousa distraißlamente e conversavam. Detivemo-nos em um grupo de cinco alunos:

As crianças não estão diretamente prestando atenção na explicação da professora, mas conversam sobre os rins: Se não beber água, já era (Marco). Júlio faz perguntas sobre os rins. Perguntam-me coisas sobre os rins: É verdade que se não beber água morre? (...) Solange coloca o corpo humano no fundo da sala. Vítor e Lucas vão ver. Tentam adivinhar o que é cada parte. Olham, examinam, conversam, perguntam. (Excerto de registro de campo)

Ainda que essas ações de aprendizagem não tenham como objeto o conhecimento científico ou teórico, apontam a existência da motivação para aprender. Como não há uma organização de ensino que empurre "a escola para dentro do mundo, tornando-a dinâmica e teoricamente poderosa no enfrentamento de problemas práticos" (Engeström, 1996, p.187, grifos do autor), configura-se uma aprendizagem encapsulada, que pouco responde a questões do cotidiano das crianças e pouco transforma os conteúdos escolares em conhecimentos para a vida.

Outro tipo de ação que pode ser caracterizada como ações de transformação refere-se às ações geradoras de motivos de aprendizagem. São ações que, a princípio, não correspondem a motivos de aprendizagem, mas, no decorrer de sua execução, produzem tais motivos. De forma geral, relacionam-se com algum interesse do sujeito.

Um exemplo emblemático dessas ações geradoras de motivos de aprendizagem refere-se ao caso de Harley, um garoto de treze anos, que já havia reprovado três vezes a $4^{\text {a }}$ série e com um largo histórico de fracasso escolar. Passou o primeiro semestre do ano letivo recusando-se a fazer a maioria das tarefas escolares. As tentativas de aproximação da professora e da pesquisadora eram frustradas e o garoto recusava nossas ofertas de ajuda e os atendimentos individualizados da professora. Além disso, tinha inúmeras ocorrências disciplinares em sua ficha de aluno e era sempre chamado à diretoria.

No segundo semestre, Harley quebra o braço e fica impedido de realizar suas ações rotineiras. Ao mesmo tempo, a professora, em muitas das aulas observadas, alerta a turma sobre a proximidade do fim do ano e a possibilidade da reprovação caso não cumpram suas tarefas adequadamente. Sugere, também, que a pesquisadora acompanhe Harley mais de perto, pois ele é um dos alunos que corre o risco de reprovar novamente. Vale lembrar que neste o início da pesquisa utilizamos como estratégia metodológica o que chamamos de situações orientadas de aprendizagem. Nesse processo de acompanhamento, uma transformação acontece:

Como Harley não pode copiar, já que está com o braço quebrado, sugiro a ele ler os poemas. Ele aceita. Ele escolhe um dos poemas e lê com dificuldades, confunde alguns sons, como, por exemplo, D com T e D com P. (...) Ele lê uma estrofe e, quando termina, leio o mesmo trecho pra ele de forma corrida. Ele se impressiona: "Olha, rimou". Diz que gostou do poema, que achou bonito. Eu leio a próxima estrofe e fazemos essa dinâmica. Ele lê uma estrofe, eu leio a outra. Quando terminamos, leio o poema inteiro. (...) Lemos todos os poemas e a leitura de Harley melhorava a cada estrofe. Quando ele terminava de ler uma estrofe, pedia para eu lê-la inteira para ver como ficou e perceber melhor as rimas (Excerto de registro de campo).

Na sequência Harley pede ajuda para escrever uma carta de amor usando os poemas lidos, conta que está apaixonado por uma garota da turma. Escrevemos a carta e o garoto, muito feliz, a entrega.

Aqui estamos diante de uma tarefa pedagógica corriqueira, a leitura e a cópia de alguns poemas, que, para Harley, normalmente, tinha pouco sentido e, portanto, gerava ações de recusa até o presente momento. Dois elementos novos aparecem nessa ação. Primeiramente, a intervenção da pesquisadora, que, ao perceber a dificuldade de leitura do estudante, cria uma estratégia para que o garoto compreenda o que está lendo e interesse-se pelo tema de estudo. Nessa unidade das ações da pesquisadora e das ações do estudante, inicia-se o processo de constituição de novos motivos para a aprendizagem. A leitura dos poemas começa a fazer sentido. E, então, outro elemento foi fundamental, o interesse de Harley por uma garota da turma motiva-o a escrever uma carta usando os poemas. $\mathrm{O}$ conteúdo escolar deixa de ser meramente escolar e torna-se um conteúdo vivo. Essa relação pouco a pouco se estende para outros conteúdos escolares e o garoto passa a pedir o auxílio da pesquisadora, começa a ler com mais fluência e chega a nos convidar para escrever junto com ele.

Neste exemplo, as ações dos estudantes iniciam-se tendo motivos alheios à atividade de estudo, a iminência da reprovação somada à impossibilidade de Harley realizar suas ações corriqueiras. A intervenção de um profissional experiente, professora ou pesquisadora, com intencionalidades pedagógicas definidas, mediada por conteúdos afetivos, produz uma nova qualidade de ação dos estudantes. Aqui aparece, ainda que de forma incipiente, novos motivos para a atividade de estudo dos estudantes, em um movimento de transformação de motivos conforme analisado por Leontiev (1974/1988).

Ressalta-se, assim, o papel do professor na produção desses novos motivos na medida em que organiza tarefas que favoreçam esse processo. Destaca-se, ainda, que a organização dessas tarefas e ações de estudo deve ser finalidade consciente do professor.

Por último, apresentamos, ainda no grupo das ações de transformação, um tipo de ação que, embora tenha ocorrido principalmente de forma empírica e não planejada, traz grandes possibilidades no que diz respeito à atribuição de sentido pessoal à atividade de estudo. São as ações coletivas de aprendizagem.

Desde nossas primeiras inserções na $4^{a}$ série, incomodava-nos a primazia das ações individualizadas com os alunos e pensávamos que outras formas de organização do ensino, mais eficientes, podiam ser produzidas. Assim, sempre que pudemos, nas situações orientadas de aprendizagem, procuramos trabalhar coletivamente com os estudantes. Segue uma dessas experiências:

Acho um livro com histórias de terror e começo a contar para Júlio e Yan. As outras crianças aproximam-se e fazem uma rodinha de contação de histórias. Yan está muito atento, pergunta onde estão 
escritas determinadas palavras. Conto duas histórias e as crianças pedem para eu contar histórias de minha cabeça. (...) Conto uma história de terror que sei, as crianças gostam, fazem perguntas, ficam com medo, resolvem contar suas histórias, cada uma conta uma história, os outros prestam atenção. (...) Todos se animam para contar, ficam com medo das histórias. (...) Todos ficam em silêncio e respeitam a vez de quem está falando. Foi um momento muito legal de proximidade com as crianças, em que elas contaram histórias, respeitaram umas às outras (Excerto de registro de campo)

Rubtsov (1996) aponta o papel das atividades realizadas em comum na formação da atividade de estudo e, a partir dos dados de suas pesquisas, mostra que "a cooperação criança/ criança favorece muito mais a formação dos alunos quanto às ações essenciais: criação de modelos, avaliação e controle" (p. 135), ações essas constituintes do pensamento teórico. Dessa forma, destaca o papel preponderante da atividade em comum, coletiva, no desenvolvimento cognitivo dos estudantes.

\section{Considerações finais}

Tendo apresentado os motivos e ações da atividade de estudo, em um segundo momento, buscamos, tendo como mediação a unidade de análise deste trabalho, os elementos que indicam quais eram os sentidos pessoais existentes, que expressam a relação entre os motivos da atividade e os fins das ações nas condições existentes em que a atividade de estudo desenvolve-se. Buscamos, também, compreender o movimento de atribuição de novos sentidos, ou sentidos possíveis. Estes últimos apontam, ainda que potencialmente, o estabelecimento de uma relação consciente com a aprendizagem escolar e sugerem a constituição da atividade de estudo como atividade principal.

Ao analisar a unidade entre o motivo "preparar para o mercado de trabalho" e as ações de cópia, considera-se que há uma ruptura entre tais elementos da atividade, pois as ações em foco não correspondem a esse motivo. O estudante não consegue estabelecer uma relação consciente entre as ações repetitivas e o motivo socialmente estabelecido vinculado ao trabalho. As ações tornam-se esvaziadas de sentido ou transformam-se em operações automatizadas, como copiar mecanicamente sem atenção ao conteúdo reproduzido. Há, assim, uma ruptura entre o significado social da atividade de estudo e o sentido que se constitui, o que dificulta ou impede que novos significados sejam aprendidos, condizentes com a possibilidade de humanização presente na atividade de estudo, e que novos sentidos constituam-se, conforme apontado por Leontiev (1974/1983) em seus estudos sobre atividade e consciência ou em Martins (2007).

A pesquisa de Temple (2010) tem constatações semelhantes em relação às práticas de cópia na sala de aula. Seu foco são as crianças copistas, mas que não sabem ler e escrever. Segundo a pesquisadora, tais crianças podem até ter apreendido o significado social de escrever, mas o sentido dessa atividade não se constituiu plenamente. O mesmo fenômeno analisado por Temple pôde ser observado nesta pesquisa.

No caso das ações disciplinares, essas podem corresponder aos motivos disciplinares. Estuda-se (ou, melhor dizendo, executam-se tarefas) para escapar de broncas, punições ou da reprovação. Embora haja uma concordância entre motivos e ações, o hiato aqui aparece entre o sentido atribuído à atividade escolar, vinculado ao disciplinamento, e o significado social da atividade de estudo, seja este "preparar para o mercado de trabalho" ou "apropriar-se do conhecimento". Significados e sentidos sofrem, assim, uma ruptura característica da consciência alienada formada em nossa sociedade.

A disciplina, que seria um meio ou conquista da atividade pedagógica, torna-se um fim em si mesma, não garantindo que ações de aprendizagem consolidem-se. Como o controle do comportamento é externo, o estudante até pode aprender a se comportar de acordo com o que é esperado socialmente, mas dificilmente desenvolve o controle da própria conduta, ou a conduta voluntária (Vigotski, 1931/1995). A constituição da livre escolha encontra-se, dessa forma, limitada. Ou, como aponta Toassa (2004, p.8), em nossa sociedade de classes, "a ontogênese da liberdade individual, como superação das leis do reflexo condicionado através da palavra, mostra-se amplamente comprometida, desde a esfera da educação até a do trabalho".

Assim, no caso da relação entre motivos e ações disciplinares, o sentido pessoal existente atribuído à atividade de estudo permanece no nível da resolução de situações imediatas, relacionando-se com novas formações psíquicas produzidas pela atividade de estudo, mas que se forma de modo alienado.

Em síntese, no processo de atribuição dos sentidos existentes, vemos dois movimentos de ruptura, de desintegração da consciência: entre os motivos da atividade e as ações; e entre os significados sociais da atividade de estudo e os sentidos.

No primeiro caso, o motivo, que é apenas compreensível para o estudante, não encontra correspondência com as ações a que é obrigado ou orientado a executar, o que torna as ações esvaziadas de sentido. Segundo Leontiev (1974/1983), há uma discordância entre o resultado objetivo das ações e os motivos da atividade. Como consequência, os conteúdos escolares pouco são conscientizados pelo sujeito, pois não ocupam um lugar estrutural em sua atividade.

No segundo caso, o sentido constituído não corresponde ao significado social da atividade de estudo, nem ao menos ao significado de senso comum vinculado à preparação para o mercado de trabalho. As significações aparecem como independentes da vida dos sujeitos, como entidades metafísicas que não correspondem à vida concreta de nossas crianças. Aqui se explicita uma análise que corrobora com a ideia de que o estudo não chega a se formar como atividade principal.

Contudo, nessas condições objetivas produtoras da consciência alienada, há contradições na condução da atividade pedagógica e na forma como os estudantes a vivenciam que apontam possibilidades concretas de resistência ao hiato entre motivos e fins das ações da atividade de estudo. Assim, é na própria relação entre motivo e fins das ações que podemos ver um sentido diferente ao que está posto, que chamamos de sentidos pessoais possíveis.

Os motivos classificados como motivos vividos, por exemplo, expressam motivos que são eficazes à atividade 
dos estudantes em foco. Dentre os motivos vividos, destacamos os afetivos, vinculados à relação com o outro. Esses motivos não condizem imediatamente com as ações de estudo, mas podem tornar-se motivos de estudo se forem transformados em mediações para tal. Na relação entre motivos afetivos e as ações produzidas, configura-se um sentido que é primeiramente emocional, relacionado à necessidade de afeto e atenção. Mas, como a relação com o outro é motivo gerador de sentido, pode ser transformado em motivo para aprendizagem dependendo de como a atividade pedagógica é organizada. No decorrer da pesquisa, tivemos muitos exemplos desse fenômeno. A atividade iniciava-se tendo como motivo a relação afetiva com a professora (ou com a pesquisadora), mas as ações desencadeadas produziam resultados em termos de aprendizagem. Essa relação entre motivos e ações parece indicar a constituição de um sentido pessoal que caminha na direção da aprendizagem e da humanização. Aqui se expressa, de forma contundente, a relação motivo-ação, pois o motivo que, inicialmente, não se relaciona à atividade de estudo é transformado pelo resultado da ação.

Há uma decorrência pedagógica importante dessa relação: a ação pedagógica bem orientada inclui a dimensão afetiva da aprendizagem que se desenvolve no processo educacional. Destaca-se, assim, que a relação sujeito e objeto do conhecimento é mediada pelo entrelaçamento dos processos cognitivos e afetivos.

Também podemos ver a constituição de sentidos possíveis na relação entre os motivos e ações de aprender. Em diferentes momentos, as crianças expressaram sua necessidade de aprender. Queriam saber sobre as coisas do mundo, especialmente sobre as coisas que as rodeiam. Realizavam ações de aprendizagem, perguntavam, pesquisavam, conversavam. Mas nem sempre a necessidade de aprender transformava-se em motivo da atividade de estudo e as ações de aprendizagem não tinham, obrigatoriamente, os conteúdos escolares como objeto.

De qualquer maneira, nessa unidade entre motivo e as ações de aprender vislumbra-se a possibilidade de formação da atividade de estudo. A necessidade de aprender, ainda que de forma incipiente, está posta. $\mathrm{O}$ objeto dessa necessidade ainda não corresponde ao conteúdo escolar, mas, quando a ação docente está orientada e atenta aos interesses discentes, é possível transformá-los em interesses de estudo. É o que vimos nas ações geradoras de motivos de aprendizagem.

Nessas ações, mediadas pelas ações do professor, pode constituir-se a unidade entre o motivo da atividade e os fins das ações, o que indica, também, o movimento de atribuição de sentido pessoal à atividade de estudo, na direção da apropriação dos conhecimentos humanos específicos da atividade pedagógica. Esboça-se a formação de uma relação consciente com os objetos do conhecimento e com a própria atividade de estudo. As ações geradoras de motivos de aprendizagem trazem a possibilidade de reconfiguração motivacional em que a busca de conhecimento torna-se um fim.

Nas ações coletivas, também há a possibilidade da constituição de sentidos pessoais possíveis à atividade de estudo.
Primeiramente porque, no caso dos estudantes em foco, analisa-se que vivenciam a comunicação íntima pessoal como atividade principal e, portanto, os amigos desempenham papel central na formação de seus interesses. Daqui surge outra decorrência pedagógica: se um dos motivos centrais para ir à escola é a relação com os colegas, torna-se essencial organizar atividades de ensino que privilegiem a coletividade. Pesquisas têm demonstrado que a atividade de estudo pautada na interação entre os estudantes produz melhores resultados em termos de aprendizagem (Rubtsov, 1996).

Para que essa unidade entre os motivos e ações estabeleça-se, seja na relação entre os motivos e ações de aprender ou motivos e ações da atividade de comunicação íntima pessoal, destaca-se a ação orientada do professor como elemento fundamental. O professor, como adulto experiente e com finalidades claramente delimitadas, deve realizar ações que criem nos estudantes motivos para o estudo e ações de aprendizagem.

Em síntese, o processo de atribuição de sentidos possíveis analisado expressa momentos de convergência entre motivos e ações na atividade de estudo em formação. Dentre eles, destacamos a necessidade de mediação afetiva no processo de aprendizagem; as ações geradoras de motivos de aprendizagem, que podem transformar a necessidade de aprender em motivos da atividade de estudo; a importância da coletividade na constituição da atividade de estudo; e a ação orientada do professor como elemento central na formação dos motivos dos estudantes. Tendo esses momentos como referência, podemos defender a tese de que, para que a aprendizagem escolar ocorra, as ações de estudo dos estudantes devem ter um sentido pessoal correspondente aos motivos e aos significados sociais da atividade de estudo, no sentido da promoção do desenvolvimento humano.

Esses momentos, agora transformados em "uma rica totalidade de determinações e relações diversas" (Marx, 1857/1989), apontam a possibilidade de uma relação consciente entre os motivos da atividade e os fins das ações, entre os significados sociais e os sentidos pessoais, e ocupam lugar de destaque para entender a estrutura da consciência e da personalidade de nossos estudantes.

\section{Referências}

Aguiar, W. M. J., \& Davis, C. L. F. (2011). Sentidos e significados no contexto escolar. Linguagem, Educação e Sociedade (UFPI), 16(25), 183-196. Recuperado de http://www.ufpi.br/subsiteFiles/ppged/arquivos/files/ Revista/les25.pdf

Asbahr, F. da S. F. (2011). Sentido pessoal, significado social e atividade de estudo: Uma revisão teórica. In Associação Brasileira de Educação e Marxismo (Org.), V Encontro Brasileiro de Educação e Marxismo.

Barros, J. P. P. Paula, L. R. C., Pascual, J. G., Colaço, V. F. R., \& Ximenes, V. M.. (2010). O conceito de "sentido" em Vygotsky: Considerações epistemológicas e suas implicações para a investigação psicológica. Psicologia \& Sociedade,21(2), 174-181. doi: 10.1590/S010271822009000200004

Bertagna, R. H. (2010). Avaliação e progressão continuada: O que a realidade desvela. Pro-Posições, 21(3), 193-218. doi:10.1590/S010373072010000300012 
Elkonin, D. B. (1987). Sobre el problema de la periodización del desarrollo psíquico e la infância. In V. Davydov \& M. Shuare (Orgs.), La psicologia evolutiva y pedagogia en la URSS: antologia. (pp. 104-124). Moscou: Editorial Progresso.

Engeström, Y. (1996). Non scolae sed vitae discimus: Como superar a encapsulação da aprendizagem escolar. In H. Daniels (Org.), Uma introdução a Vygotsky (pp. 175-197). São Paulo: Loyola.

Gatti, B. A. (2005). Grupo focal na pesquisa em ciências sociais e humanas. Brasília: Líber livro.

Leontiev, A. (1983) Actividad, conciencia e personalidad. Havana: Pueblo y Educacion. (Obra original publicada em 1974)

Leontiev, A (1988). Uma contribuição à teoria do desenvolvimento da psique infantil. In L. S. Vigotskii; A. R. Luria, \& A. N. Leontiev (Orgs.), Linguagem, desenvolvimento e aprendizagem. (5ae ed., pp. 59-83). São Paulo: Ícone. (Obra original publicada em 1944)

Lima, L. C. A. (2011). Da universalização do ensino fundamental ao desafio de democratizar o ensino médio em 2016: O que evidenciam as estatísticas? Revista Brasileira de Estudos Pedagógicos, 92(231), 268-284. Recuperado de http://rbep.inep.gov.br/index.php/RBEP/issue/view/124/showToc

Martins, L. M. (2007). A Formação Social da personalidade do professor: Um enfoque vigotskiano. Campinas: Autores Associados.

Martins, L. M., \& Eidt, N. (2010). Trabalho e Atividade: Categorias de análise da psicologia histórico-cultural do desenvolvimento. Psicologia em Estudo, 15 675-683. doi: 10.1590/S1413-73722010000400003

Marx, K. (1989). O método da economia política. In F. Fernandes (Org), Marx e Engels: História. (pp. 409-417). São Paulo: Ática. (Obra original publicada em 1857)

Paro, V. H. (1999). Parem de preparar para o trabalho! Reflexões acerca dos efeitos do neoliberalismo sobre a gestão e o papel da escola básica. In C. J. Ferreti, J. R. Silva Jr., \& M. R. N. S. Oliveira (Orgs.), Trabalho, formação e Currículo: Para onde vai a escola? (pp. 101-120). São Paulo: Xamã.

Paro, V. H. (2001). Reprovação escolar: renúncia à educação. São Paulo: Xamã

Patto, M. H. S. (1999). A produção do fracasso escolar: Histórias de submissão e rebeldia. São Paulo: Casa do Psicólogo.

Rey, F. L. G. (2009). Las categorias de sentido, sentido personal y sentido subjetivo en una perspectiva histórico-cultural: un camino hacia una nueva definición de subjetividad. Universitas Psychologica, 9, 241-253. Recuperado de http://www.scielo.org.co/scielo.php?script=sci_arttext\&pid=S165792672010000100019\&lng=pt\&tlng=es

Rockwell, E. (2009). La experiencia etnográfica. História y cultura en los procesos educativos. Buenos Aires: Paidós.

Rubtsov, V. V. (1996). A atividade de aprendizado e os problemas referentes à formação do pensamento teórico dos escolares. In C. Garnier, N. Bednarz, \& I. Ulanovskaya (Orgs.), Após Vygotsky e Piaget: Perspectivas social e construtivista - escolas russa e ocidental. (pp. 129-137). Porto Alegre, RS: Artes Médicas.

Souza, M. P. R. (2010). Ouvindo crianças na escola: Abordagens qualitativas e desafios metodológicos para a psicologia. São Paulo: Casa do Psicólogo.

Temple, G. C. (2010). A escrita na perspectiva histórico-cultural: Metodologia etnográfica de pesquisa. In M. P. R Souza (Org.), Ouvindo crianças na escola: Abordagens qualitativas e desafios metodológicos para a psicologia (pp. 229256). São Paulo: Casa do Psicólogo.

Toassa, G. (2004). Conceito de liberdade em Vigotski. Psicologia, ciência e profissão. 24(3), 2-11. doi: 10.1590/S1414-98932004000300002

Viégas, L. S. (2007). Progressão continuada em uma perspectiva crítica em psicologia escolar: história, discurso oficial e vida diária escolar (Tese de doutorado) Instituto de Psicologia, Universidade de São Paulo, São Paulo. Recuperado de http://www.teses.usp.br/teses/disponiveis/47/47131/tde-06052008 171129/pt-br.php

Vigotski, L. S. (2000). A construção do pensamento e da linguagem. São Paulo: Martins Fontes. (Obra original publicada em 1934)
Vigotski, L. S. (2000a). Manuscrito de 1929 (Psicologia concreta do homem). Educação \& Sociedade, 21(71), 21-44. (Obra original publicada em 1929). doi: 10.1590/S0101-73302000000200002

Vygotski, L. S. (1995). Obras escogidas (vol. 3). Madrid: Machado Libros. (Obra original publicada em 1931) 
Flávia da Silva Ferreira Asbahr, Doutora em Psicologia Escolar e do Desenvolvimento Humano pelo Instituto de Psicologia da Universidade de São Paulo (IP-USP), é Professora assistente do Departamento de Psicologia da Faculdade de Ciências na Universidade Estadual Júlio de Mesquita Filho (UNESP), Campus de Bauru. Endereço para correspondência: Departamento de Psicologia , Faculdade de Ciências de Bauru, Universidade Estadual Paulista Júlio de Mesquita Filho , Av. Eng ${ }^{\circ}$ Luiz Edmundo Carrijo Coube, $n^{\circ}$ 14-01, Vargem Limpa, CEP: 17033-360 - Bauru, SP - Brasil. Telefone: (14) 31036087. E-mail: flavia. asbahr@fc.unesp.br

Marilene Proença Rebello de Souza, Doutora em Psicologia Escolar e do Desenvolvimento Humano pela Universidade de São Paulo (USP), é Professora Livre-Docente em Psicologia Escolar e do Desenvolvimento Humano pelo Instituto de Psicologia da Universidade de São Paulo (IP-USP), é Coordenadora de PósGraduação do Instituto de Psicologia da Universidade de São Paulo (CPG/IP/USP). E-mail: mprdsouz@ usp.br 